\title{
Erratum to: Intra-articular hip injection: does pain relief correlate with radiographic severity of osteoarthritis?
}

\author{
Ajit J. Deshmukh • Georgia Panagopoulos • \\ Ahmadreza Alizadeh • Jose A. Rodriguez • \\ Devon A. Klein
}

Published online: 28 June 2012

(C) ISS 2012

\section{Erratum to: Skeletal Radiol \\ DOI 10.1007/s00256-011-1120-8}

This is with reference to our article in Skeletal Radiology: Deshmukh AJ, Panagopoulos G, Ahmadreza A, Rodriguez JA, Klein DA "Intra-articular Hip Injection: Does Pain Relief Correlate With Radiographic Severity of Osteoarthritis?" Skeletal Radiology 2011; Volume 40, Issue 11, Page 1449-1454.

It has been rightly brought to our attention by Dr. Y. V. Kleinlugtenbelt, Department of Orthopaedic Surgery, OLVG Amsterdam, that we made a mistake in Table 3 and as a result, Fig 2. In Table 3, instead of percentages, actual frequencies were included. This does not change the trend or conclusion of the paper, but we would like to notify the readers nevertheless.

Thanking You,

Sincerely,

Ajit J. Deshmukh, MD

05/05/12

The online version of the original article can be found at http:/ dx.doi.org/10.1007/s00256-011-1120-8.

A. J. Deshmukh $(\bowtie) \cdot$ G. Panagopoulos $\cdot$ J. A. Rodriguez Department of Orthopaedic Surgery,

North Shore LIJ Lenox Hill Hospital,

130E 77th Street 11th Floor,

New York, NY 10075, USA

e-mail: drajitdeshmukh@gmail.com

A. Alizadeh · D. A. Klein

Department of Radiology, North Shore LIJ Lenox Hill Hospital,

100E 77th Street 3rd Floor,

New York, NY 10075, USA 